\title{
Comparison of the effects of inhibitors of aldose reductase and sorbitol dehydrogenase on neurovascular function, nerve conduction and tissue polyol pathway metabolites in streptozotocin-diabetic rats
}

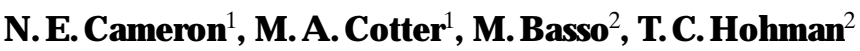 \\ ${ }^{1}$ Department of Biomedical Sciences, University of Aberdeen, Scotland, UK \\ ${ }^{2}$ Wyeth-Ayerst Research, Princeton, New Jersey, USA
}

Summary Aldose reductase inhibitors (ARIs) attenuate diabetic complications in several tissues, including lens, retina, kidney, blood vessels, striated muscle and peripheral nerve. However, it is unclear whether their action in diabetes mellitus depends directly on inhibiting the conversion of glucose to sorbitol by aldose reductase or indirectly by reducing the sorbitol available for subsequent metabolism to fructose by sorbitol dehydrogenase. To identify the polyol pathway step most relevant to complications, particularly neuropathy, we compared the biochemical effects of a sorbitol dehydrogenase inhibitor, WAY-135706, $\left(250 \mathrm{mg} \cdot \mathrm{kg}^{-1} \cdot \mathrm{day}^{-1}\right)$ and an ARI, WAY-121509, $\left(10 \mathrm{mg} \cdot \mathrm{kg}^{-1} \cdot \mathrm{day}^{-1}\right)$ on a variety of tissues, and their effects on nerve perfusion and conduction velocity. After 6 weeks of untreated streptozotocin diabetes, rats were treated for 2 weeks. Sorbitol was elevated 2.1-32.6-fold by diabetes in lens, retina, kidney, aorta, diaphragm, erythrocytes and sciatic nerve; this was further increased (1.6-8.2-fold) by WAY-135706 whereas WAY-121509 caused a marked reduction. Fructose 1.6-8.0-fold elevated by diabetes in tissues other than diaphragm, was reduced by WAY-135706 and WAY-121509, except in the kidney. Motor and sensory nerve conduction velocities were decreased by 20.2 and $13.9 \%$, respectively with diabetes. These deficits were corrected by WAY-121509, but WAY135706 was completely ineffective. A $48.6 \%$ diabetes-induced deficit in sciatic nutritive endoneurial blood flow was corrected by WAY-121509, but was unaltered by WAY-135706. Thus, despite profound sorbitol dehydrogenase inhibition, WAY-135706 had no beneficial effect on nerve function. The data demonstrate that aldose reductase activity, the first step in the polyol pathway, makes a markedly greater contribution to the aetiology of diabetic neurovascular and neurological dysfunction than does the second step involving sorbitol dehydrogenase. [Diabetologia (1997) 40: 271-281]

Keywords Aldose reductase, sorbitol dehydrogenase, myo-inositol, ocular tissues, kidney, aorta, muscle, nerve conduction, nerve blood flow, diabetic rat.
Elevated polyol pathway activity has been implicated in the development of diabetic complications, including neuropathy [1]. In diabetic models, inhibitors of

Received: 13 August 1996 and in final revised form: 6 December 1996

Corresponding author: Dr. N. E. Cameron, Department of Biomedical Sciences, University of Aberdeen, Marischal College, Aberdeen AB9 1AS, Scotland, UK

A bbreviations: AGE, Advanced glycation end product; ARI, aldose reductase inhibitor; NCV, nerve conduction velocity; SDI, sorbitol dehydrogenase inhibitor. the first enzyme in the pathway, aldose reductase, prevent or correct nerve conduction velocity (NCV) and regeneration deficits [2-13]. Clinical trials of aldose reductase inhibitors (ARIs) have shown modest improvements in neurological symptoms, NCV, sensory measures, and an increase in nerve fibre regeneration [14-17] despite a less effective polyol pathway blockade than was found necessary for functional effects in animal studies $[6,10,18]$.

Several hypotheses have been advanced to explain the action of ARI. Some putative mechanisms are primarily dependent on the first half of the polyol pathway, conversion of glucose to sorbitol by aldose 
reductase. These include the prevention of tissue sorbitol accumulation and sequelae consequent on the resultant osmotic imbalance such as reduced nerve myo-inositol $[19,20]$, and deleterious effects on $\mathrm{Na}^{+}-$ $\mathrm{K}^{+}$ATPase activity [21]. Aldose reductase requires $\mathrm{NADPH}$ as a co-factor, and depletion by elevated flux through the polyol pathway could alter the glutathione redox cycle, which would diminish protection against reactive oxygen species [22]. NADPH is also necessary for nitric oxide synthesis and the maintenance of vascular tone. These latter mechanisms have been linked to reduced nerve perfusion and oxygen supply $[6,10,23-26]$ which make major contributions to nerve dysfunction in diabetic patients and experimental models [27-29]. In contrast, other hypotheses consider the second half of the polyol pathway, conversion of sorbitol to fructose by sorbitol dehydrogenase, as the most important in the pathogenesis of diabetic complications including neuropathy. Fructose is a more effective glycating agent than glucose and advanced glycation end product (AGE) formation may contribute to diabetic complications [30]. Flux through the second part of the pathway also causes an increase in the NADH/NAD ${ }^{+}$ratio which has been hypothesised to cause a state of "hyperglycaemic pseudohypoxia" [31] which may contribute to neuropathy independent of changes in nerve perfusion $[32,33]$.

Recently, specific sorbitol dehydrogenase inhibitors (SDIs) have become available [34]. Therefore, the aims of this study were to compare the biochemical effects of a pyrimidine-based SDI, WAY-135706, with that of the ARI, WAY-121509 [10, 11, 35] in tissues prone to diabetic complications, and to investigate the relative importance of the two enzymes of the polyol pathway for motor and sensory NCV and nerve blood flow abnormalities.

\section{Materials and methods}

The experiments were performed in accordance with regulations specified by the United Kingdom 'Animal Procedures Act, 1986' and the National Institutes of Health 'Principles of Laboratory Animal Care, 1985 revised version'.

Experimental groups and diabetes induction. Two studies were performed in which diabetes duration was 8 weeks and drug treatment was given over the final 2 weeks. Diabetes was induced by i.p. injection (40-45 $\mathrm{mg} \cdot \mathrm{kg}^{-1}$ ) of streptozotocin (Sigma, St. Louis, Mo., USA or Zeneca, Macclesfield, UK) in mature 19-week-old male Sprague-Dawley rats obtained either from Charles River (Kingston, N. Y., USA) or from Aberdeen University breeding colony. Study 1, performed in Princeton, examined the levels of polyol pathway metabolites and myoinositol in lens, sciatic nerve, retina, renal cortex and medulla, and erythrocytes. Study 2, carried out in Aberdeen, was mainly concerned with measures of nerve function and vascular supply although nerve, aorta and diaphragm were also taken for polyol analysis.
In both studies the following groups were used: non-diabetic and diabetic controls, diabetic and non-diabetic rats treated with the SDI, WAY-135706 (2-hydroxymethyl-4-(4-(N ,N dimethylaminosulfonyl-1-piperazino) pyrimidine), added to the food or the drinking water to yield a daily dose of approximately $250 \mathrm{mg} \cdot \mathrm{kg}^{-1}$, and diabetic rats treated with the ARI, WAY-121509 [10, 11, 35], added to the diet to yield a daily dose of approximately $10 \mathrm{mg} \cdot \mathrm{kg}^{-1}$. A pilot study examined the action of a lower SDI dose $\left(100 \mathrm{mg} \cdot \mathrm{kg}^{-1} \cdot \mathrm{day}^{-1}\right)$ on sciatic motor NCV. Choice of the main SDI dose was based on this study, being increased to assess whether a greater NCV effect was possible.

For study 1 and 2, tissues were removed, frozen in liquid $\mathrm{N}_{2}$ or solid $\mathrm{CO}_{2}$ and stored at $-80^{\circ} \mathrm{C}$ before carbohydrate analysis. In study 1 , kidneys were first perfused via the renal artery with sterile saline at $37^{\circ} \mathrm{C}$ to eliminate contamination by erythrocytes.

Tissue carbohydrates. Tissue glucose, sorbitol, fructose and myo-inositol concentrations were measured as their aldonitrile and cyclitol or alditol acetate derivatives as previously described $[10,11,36]$, using gas liquid chromatography and mass spectrometry detection. Protein content was estimated by the method of Peterson [37].

Nerve conduction velocity. In final experiments for study 2 , rats were anaesthetised with thiobutabarbitone (Zeneca) by i.p. injection $\left(50-100 \mathrm{mg} \cdot \mathrm{kg}^{-1}\right)$. The trachea was cannulated for artificial ventilation and a carotid cannula was used to monitor mean systemic blood pressure. This surgery took approximately 10-15 min. Motor conduction velocity was measured between sciatic notch and knee for the nerve branch to tibialis anterior muscle as previously described [6]. In a subset of rats not used for blood flow determination, sensory NCV in saphenous nerve was also estimated [24].

Nerve blood flow. Sciatic endoneurial blood flow was measured in the contralateral leg using microelectrode polarography and hydrogen clearance as previously described [6, 10, 38]. Briefly, rats were given neuromuscular blockade using dtubocurarine (Sigma, $2 \mathrm{mg} \cdot \mathrm{kg}^{-1}$ via the carotid cannula) and were artificially ventilated (rate approximately $60 \mathrm{~min}^{-1}$, ventilation volume approximately $2.5 \mathrm{ml}$ ). The level of anaesthesia was monitored by observing any reaction of blood pressure to manipulation, and supplementary thiobutabarbitone was given as necessary. Body core temperature was maintained at 37$38^{\circ} \mathrm{C}$ and nerve temperature was controlled within the range $35-37^{\circ} \mathrm{C}$ by radiant heat applied to a mineral oil pool that bathed the exposed sciatic nerve. A micromanipulator-mounted glass-insulated $\mathrm{H}_{2}$-sensitive platinum microelectrode was inserted into the middle portion of the nerve. $10 \% \mathrm{H}_{2}$ was added to the inspired gas, the proportions of $\mathrm{O}_{2}$ and $\mathrm{N}_{2}$ being adjusted to 20 and $70 \%$, respectively. When the electrode $\mathrm{H}_{2}$ current had stabilised, the $\mathrm{H}_{2}$ supply was shut off and the clearance monitored. This was repeated at another nerve site more than $4 \mathrm{~mm}$ proximal or distal. Mono- or bi-exponential curves were fitted to the data by regression analysis (Prism; Graphpad, San Diego, Calif., USA) [39]. The fitting procedure gave $r^{2}$ values within the range $0.997-1.000$ for all individual curves in this study. The slow exponent was taken to reflect nutritive capillary flow, and the fast exponent non-nutritive flow [27]. Composite (total) endoneurial flow was defined as the weighted sum of fast and slow components. The percentage of nutritive clearance was determined from the weighting coefficients for slow and fast components [10]. Vascular conductance was calculated by dividing blood flow by mean arterial blood pressure determined during the recording period. The average for 


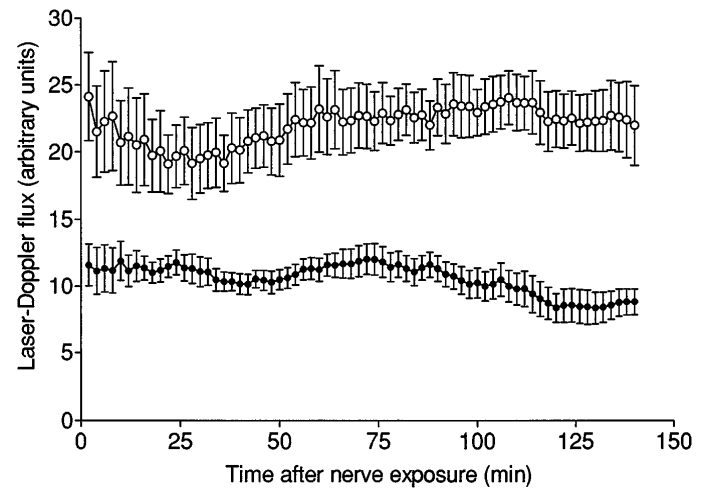

Fig. 1. Time course of the effects of nerve exposure on laserDoppler blood flow in rats. Non-diabetic group $(O), \mathrm{n}=10$; diabetic group $(\bullet), n=8$. Data are means \pm SEM

Table 1. Body weights and plasma glucose concentrations

\begin{tabular}{llllc}
\hline Group & \multicolumn{2}{c}{ Weight $(\mathrm{g})$} & Plasma glucose \\
\cline { 3 - 4 } & $\mathrm{n}$ & Start & End & $\left(\mathrm{mmol} \cdot \mathrm{l}^{-1}\right)$ \\
\hline Non-diabetic & 20 & & $505 \pm 15$ & $6.8 \pm 0.2$ \\
Non-diabetic + SDI & 24 & & $466 \pm 8$ & $6.6 \pm 0.2$ \\
Diabetic & 20 & $466 \pm 5$ & $391 \pm 19^{\mathrm{a}}$ & $36.7 \pm 1.6^{\mathrm{a}}$ \\
Diabetic + SDI & 27 & $464 \pm 6$ & $359 \pm 16^{\mathrm{a}}$ & $35.7 \pm 1.7^{\mathrm{a}}$ \\
Diabetic + ARI & 21 & $484 \pm 4$ & $417 \pm 13^{\mathrm{b}}$ & $35.9 \pm 1.8^{\mathrm{a}}$ \\
\hline
\end{tabular}

Data are means \pm SEM

${ }^{\mathrm{a}} \mathrm{p}<0.001 ;{ }^{\mathrm{b}} \mathrm{p}<0.01$ vs non-diabetic group

the two clearance measurements was taken to represent sciatic endoneurial blood flow perfusion parameters.

One group of investigators has suggested that the reduced nerve blood flow in diabetic rats is a methodological artefact resulting from an inflammatory response in exposed nerves $[32,40]$. Based on microsphere entrapment experiments, it was proposed that while blood flow in diabetic and non-diabetic nerves is initially equivalent, over a 2 -h period, an inflammatory vasodilation, which is blunted in diabetic rats, produces a 2-3-fold blood flow increase in non-diabetic rats. This would result in an apparent relative decrease in nerve blood flow for diabetic rats. However, the application of the microsphere method to the measurement of nerve blood flow is questionable [24, 27, 28, 41] and other techniques that do not involve nerve exposure also show reduced nerve blood flow in diabetic rats [42]. Whether or not an operative procedure causes a significant inflammatory response depends critically on the degree of tissue trauma. Therefore, this point was examined in a pilot experiment where non-diabetic $(n=10)$ and 2-month diabetic $\left(n=8\right.$; plasma glucose $\left.43.8 \pm 1.6 \mathrm{mmol} \cdot \mathrm{l}^{-1}\right)$ rats were prepared for sciatic nerve blood flow measurement as described above but instead of hydrogen clearance measurements, flow changes were monitored using a laser-Doppler device $\left(\mathrm{BPM}^{2}\right.$ Laserflo; Vincent Medical, Slough, Bucks., UK), with a $0.8-\mathrm{mm}$ diameter probe [43]. Readings were taken within $2 \mathrm{~min}$ of nerve exposure and at 2-min intervals for $140 \mathrm{~min}$. A $51.9 \pm 5.7 \%$ reduction $(p<0.0001$, Mann-Whitney U test $)$ in laser-Doppler flux (Fig. 1) was found within 2 min of nerve exposure in diabetic compared to non-diabetic rats and this deficit was maintained over the 140-min recording period, the average values being $22.0 \pm 2.3$ and $10.6 \pm 0.8$ laser-Doppler flux units in non-diabetic and diabetic groups, respectively $(p<0.0001)$. Mean systemic blood pressure during the recording period was lower in diabetic $(115.7 \pm 6.7 \mathrm{~mm} \mathrm{Hg})$ than non-diabetic $(141.7 \pm 2.5 \mathrm{~mm} \mathrm{Hg})$ rats $(p<0.0001)$. However, when this was taken into account by calculating vascular conductance, start and average values remained depressed $(p<0.0001)$ by diabetes $(0.101 \pm 0.015$ and $0.092 \pm 0.005$ laserDoppler flux units $\cdot \mathrm{mm} \mathrm{Hg}^{-1}$, respectively) compared to the non-diabetic group $(0.167 \pm 0.022$ and $0.155 \pm 0.016$ laser-Doppler flux units $\left.\cdot \mathrm{mm} \mathrm{Hg}^{-1}\right)$. There was no indication of a systematic increase in laser-Doppler flux over the course of the experiments in non-diabetic or diabetic groups. For the former, this agrees with previously reported measurements over a 4-h period [44]. The deficit in laser-Doppler flux with diabetes also agrees with several reports [6, 8, 43, 45-48]. It was further suggested that reduced blood flow in diabetic rats is only found when they are ketotic [49]. Measurements of plasma $\beta$-hydroxybutyrate using a standard test kit (Sigma), however, were not significantly different between diabetic and non-diabetic groups $\left(4.9 \pm 1.5 \mathrm{vs} 2.1 \pm 0.8 \mathrm{mg} \cdot \mathrm{dl}^{-1}\right)$. Thus, in this diabetic model and under the experimental conditions used in this laboratory, nerve blood flow measured by hydrogen clearance microelectrode polarography gives an assessment of endoneurial perfusion uncontaminated by putative artefacts due either to ketosis or to inflammatory reactions caused by excessive tissue damage.

Statistical analysis. Data were subjected to Bartlett's test for homogeneity of variance, and then to $\log$ transformation if necessary before one-way analysis of variance. Where overall significance $(p<0.05)$ was attained, individual between-group comparisons were made using the Student-Newman-Keuls range test to correct for multiple comparisons. When between-group variance differences could not be normalised by log transformation (body weights, plasma glucose, and some of the biochemical data), the Kruskal-Wallace non parametric analysis of variance was followed by Dunn's multiple comparison test.

\section{Results}

There was an approximate 5.4-fold increase in plasma glucose and $17.8 \%$ decrease in body weight with diabetes, which were not significantly altered by SDI or ARI treatment (Table 1).

Tissue carbohydrate levels from study 1 (nerve, lens, retina, kidney and erythrocytes) and study 2 (aorta and diaphragm) are shown in Table 2. Glucose concentrations were elevated approximately 515 fold by diabetes, regardless of SDI or ARI treatment. Nerve sorbitol was increased 12-fold in untreated diabetic rats and this was matched in SDItreated non-diabetic rats. In the diabetic groups, ARI treatment suppressed sorbitol below the non-diabetic level whereas SDI treatment caused a 3.6-fold increase above levels found in untreated diabetic rats. Fructose concentration was increased 6.3-fold by diabetes. ARI treatment reduced fructose by $84 \%$ below the non-diabetic value. SDI treatment caused similar marked reductions in non-diabetic (92\% vs non-diabetic control group) and diabetic (69\% vs non-diabetic control group) rats. Nerve myo-inositol content was $40 \%$ decreased by diabetes and sorbitol accumulation in SDI-treated 
Table 2. Tissue carbohydrate concentrations

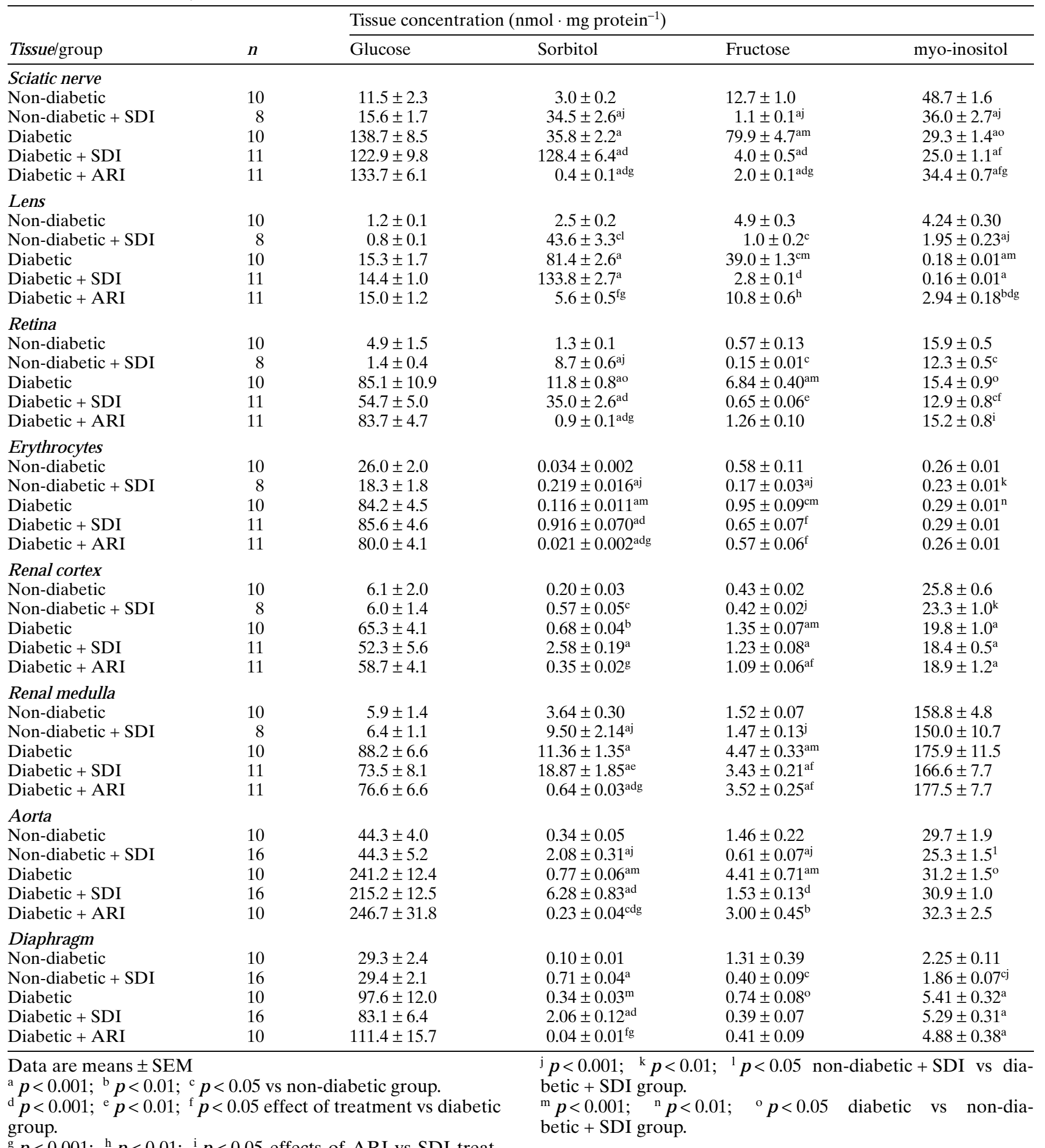

${ }_{\mathrm{g}} \mathrm{p}<0.001 ;{ }^{\mathrm{h}} \mathrm{p}<0.01 ;{ }^{\mathrm{i}} \mathrm{p}<0.05$ effects of ARI vs SDI treatment of diabetic rats.

non-diabetic rats was also accompanied by a $26 \%$ myo-inositol loss. ARI-treatment of diabetic rats caused a partial correction of myo-inositol content. In SDI-treated diabetic rats there was a tendency for a further myo-inositol decrease below levels found in SDI-treated non-diabetic rats, although this was not statistically significant. Nerve water content, $1.401 \pm 0.074 \mathrm{mg} \cdot \mathrm{mg}$ dry weight ${ }^{-1}$ in the non-diabetic group, was increased to $1.751 \pm 0.107$ and $1.815 \pm 0.108 \mathrm{mg} \cdot \mathrm{mg}$ dry weight ${ }^{-1}$ in diabetic and 
SDI-treated diabetic groups, respectively $(p<0.05)$, whereas there was no significant increase in SDItreated non-diabetic $(1.457 \pm 0.098 \mathrm{mg} \cdot \mathrm{mg}$ dry weight $\left.^{-1}\right)$ or ARI-treated diabetic $(1.551 \pm 0.034 \mathrm{mg}$. mg dry weight ${ }^{-1}$ ) rats.

Nerve polyol pathway metabolites were also measured in the Aberdeen colony rats used for NCV and blood flow determinations (Study 2). The results (data not shown) were in good agreement with those from the biochemical study above; a $13.5 \pm 3.1$-fold $(p<0.001)$ increase in sorbitol with diabetes was further increased $3.1 \pm 0.3$-fold $(p<0.001)$ with SDI treatment whereas ARI treatment suppressed sorbitol to $7.9 \pm 0.1 \%(p<0.001)$ of the non-diabetic value. SDI treatment of non-diabetic rats caused a $19.2 \pm 2.1$-fold increase in nerve sorbitol to a value slightly higher $(p<0.05)$ than found with untreated diabetes. Fructose concentration, 4.2 \pm 0.3 -fold $(p<0.001)$ increased by diabetes, was reduced to below the non-diabetic level by both SDI $(30.8 \pm 2.3 \%$, $p<0.001)$ and ARI $(13.4 \pm 1.3 \%, p<0.001)$ treatment of diabetic rats and SDI treatment of non-diabetic rats $(9.3 \pm 1.2 \%, p<0.001)$. The plasma halflife of the SDI inhibitor is not known, although it has been suggested to be less than $1 \mathrm{~h}$ [33]. If that figure is accurate, then a waning of biochemical effects could have occurred during the time required to make the functional measurements. To examine this possibility, nerve fructose concentrations were compared in rats used only for NCV $(\sim 30 \mathrm{~min})$ or blood flow $(\sim 2-3 \mathrm{~h})$ measurements. Fructose remained reduced below the non-diabetic and diabetic levels by $71.3 \pm 5.8 \%$ and $93.1 \pm 1.4 \%$, respectively for SDItreated diabetic rats $(n=6)$ used only for $\mathrm{NCV}$, and by $67.9 \pm 1.6 \%$ and $92.3 \pm 0.4 \%$ for SDI-treated diabetic rats $(n=10)$ used for blood flow measurements. For SDI-treated non-diabetic rats, fructose was $88.7 \pm 2.9 \%$ depressed in the NCV only subgroup $(\mathrm{n}=6)$ and $92.0 \pm 0.9 \%$ in the blood flow subgroup $(\mathrm{n}=10)$. Thus, the SDI was effective with no evidence of a decline in the degree of inhibition during functional measurements.

Although absolute levels of carbohydrates varied considerably between tissues, the patterns of ARI and SDI effects on sorbitol in lens, retina, renal cortex and medulla, erythrocytes, aorta and diaphragm (Table 2) were similar to that for nerve. Elevated sorbitol in diabetes was prevented by ARI whereas it was exacerbated by SDI treatment. In non-diabetic rats, SDI treatment caused sorbitol levels to roughly match those of untreated diabetes. In contrast both ARI and SDI treatments suppressed lens, retina and erythrocyte fructose concentrations. In aorta, fructose suppression by the SDI was only partial, and was not statistically significant for ARI treatment. For diaphragm, fructose levels were not increased by diabetes or markedly altered by the inhibitors. Renal cortex and medulla fructose concentrations were

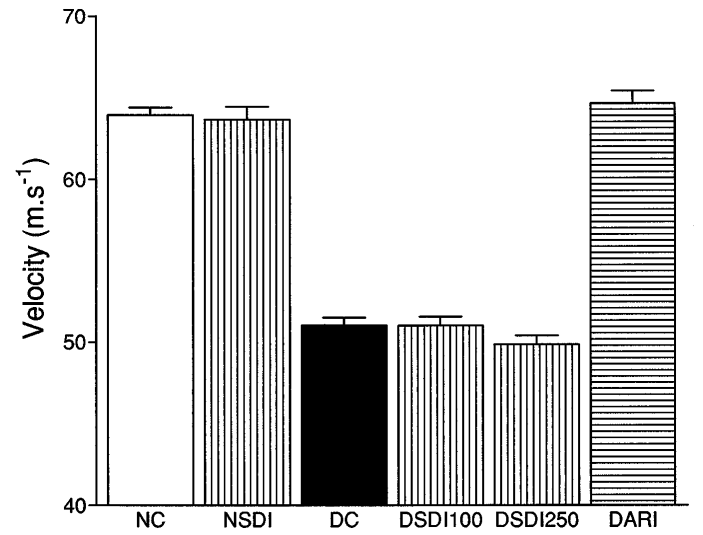

Fig. 2. Effects of diabetes, sorbitol dehydrogenase and aldose reductase inhibitors on sciatic motor conduction velocity in rats. $\mathrm{NC}$, non-diabetic group, $\mathrm{n}=10$; NSDI, non-diabetic group treated for 2 weeks with the sorbitol dehydrogenase inhibitor, WAY-135706 $\left(250 \mathrm{mg} \cdot \mathrm{kg}^{-1} \cdot \mathrm{day}^{-1}\right), \mathrm{n}=8$; DC, 8-week diabetic control group, $n=10$; DSDI100, 8-week diabetic group treated for the final 2 weeks with WAY-135706 $\left(100 \mathrm{mg} \cdot \mathrm{kg}^{-1}\right.$ - day $\left.^{-1}\right), \mathrm{n}=9$; DSDI250, 8-week diabetic group treated for the final 2 weeks with WAY-135706 $\left(250 \mathrm{mg} \cdot \mathrm{kg}^{-1} \cdot \mathrm{day}^{-1}\right)$, $\mathrm{n}=8$; DARI, 8-week diabetic group treated for the final 2 weeks with WAY-121509 $\left(10 \mathrm{mg} \cdot \mathrm{kg}^{-1} \cdot \mathrm{day}^{-1}\right), \mathrm{n}=10$. Data are mean \pm SEM. Statistics: NC vs DC, DSDI100, DSDI250, $p<0.001 ;$ DC vs DARI, $p<0.001 ;$ DARI vs DSDI100, DSDI250, $p<0.001 ;$ NSDI vs DSDI250, $p<0.001$

elevated by diabetes but only modestly reduced by ARI or SDI treatment. In non-diabetic rats, SDI treatment did not significantly reduce fructose levels in renal tissues, and caused only a modest reduction in diaphragm. However, fructose was markedly reduced by the SDI in lens, retina, erythrocytes and aorta.

Myo-inositol changes varied between tissues and with diabetes and treatment. In lens, as in nerve, myo-inositol was reduced by diabetes and partially corrected by ARI treatment. SDI treatment of nondiabetic rats depressed lens myo-inositol content. In retina, diabetes and ARI treatment had no effect on myo-inositol concentrations; however, SDI treatment reduced retinal myo-inositol in both diabetic and non-diabetic rats. Diabetes had no effect on myoinositol levels in renal medulla, erythrocytes or aorta. Renal cortex myo-inositol was depressed by diabetes and unaffected by ARI or SDI treatments. Conversely, in diaphragm, myo-inositol was markedly elevated by diabetes, but ARI and SDI treatments had no effect. Myo-inositol and sorbitol content were inversely correlated when data from untreated and treated diabetic groups were pooled for nerve $\left(r^{2}=0.498, \quad p<0.0001\right)$ and lens $\left(r^{2}=0.786\right.$, $p<0.0001$ ) but no significant correlation was found for retina, erythrocytes, renal cortex and medulla, aorta or diaphragm.

Sciatic motor NCV (Fig. 2) was $20.2 \pm 0.7 \%$ reduced $(p<0.001)$ by 8 weeks of diabetes. ARI treatment with WAY-121509 for the last 2 weeks 


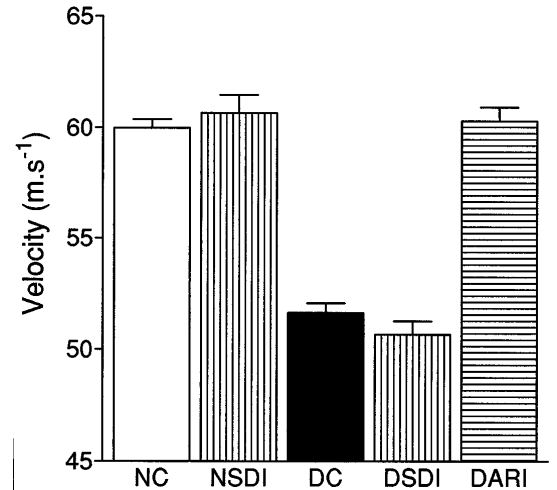

Fig. 3. Effects of diabetes, sorbitol dehydrogenase and aldose reductase inhibitors on saphenous sensory conduction velocity in rats. NC, non-diabetic group, $\mathrm{n}=10$; NSDI, non-diabetic group treated for 2 weeks with the sorbitol dehydrogenase inhibitor, WAY-135706 $\left(250 \mathrm{mg} \cdot \mathrm{kg}^{-1} \cdot \mathrm{day}^{-1}\right), \mathrm{n}=8 ; \mathrm{DC}$, 8 week diabetic control group, $n=10$; DSDI, 8 week diabetic group treated for the final 2 weeks with WAY-135706 $\left(250 \mathrm{mg} \cdot \mathrm{kg}^{-1} \cdot \mathrm{day}^{-1}\right), \mathrm{n}=8$; DARI, 8 week diabetic group treated for the final 2 weeks with WAY-121509 (10 mg . $\mathrm{kg}^{-1} \cdot$ day $\left.^{-1}\right), \mathrm{n}=7$. Data are mean + SEM. Statistics: NC vs DC, DSDI, $p<0.001$; DC vs DARI, $p<0.001$; DARI vs DSDI, $p<0.001$; NSDI vs DSDI, $p<0.001$

completely corrected the NCV deficit $(p<0.001)$. This contrasts with SDI treatment, where motor $\mathrm{NCV}$ remained within the diabetic range for doses of 100 and $250 \mathrm{mg} \cdot \mathrm{kg}^{-1}$, significantly reduced compared to non-diabetic $(p<0.001)$ and ARI-treated diabetic $(p<0.001)$ groups. A similar outcome was apparent for saphenous sensory NCV (Fig. 3); the $13.9 \pm 0.7 \%$ deficit with diabetes $(p<0.001)$ was completely corrected by ARI treatment $(p<0.001)$ while remaining totally resistant to the high SDI dose.

There was a $48.6 \pm 2.9 \%$ reduction $(p<0.001)$ in sciatic nutritive (capillary) endoneurial blood flow (Fig. 4 A) with diabetes which was $77.9 \pm 7.8 \%$ corrected by ARI treatment although a small $(10.8 \pm 3.8 \%)$ but significant $(p<0.05)$ deficit remained. SDI treatment of diabetic rats did not significantly alter blood flow, which remained in the lower half of the diabetic range, significantly reduced compared to non-diabetic $(p<0.001)$ or ARI-treated diabetic $(p<0.001)$ groups. For SDI-treated non-diabetic rats, blood flow was slightly $(15.5 \pm 3.8 \%$, $p<0.01)$ reduced compared to the non-diabetic group. There were between-group variations in mean systemic blood pressure (Fig. 4B) recorded during the hydrogen clearance measurements, with significant reductions in diabetic and ARI-treated diabetic groups compared to non-diabetic rats $(p<0.05)$. Differences in perfusion pressure may have contributed to the flow changes with diabetes and treatment as vasa nervorum has a minimal capacity for pressure autoregulation [27]. When this is taken into account by expressing the data as
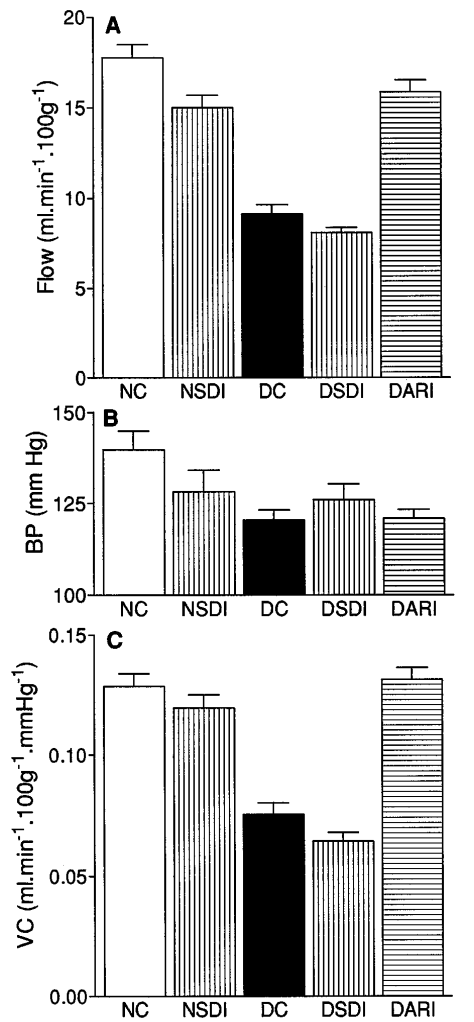

Fig.4A -C. Effects of diabetes, sorbitol dehydrogenase and aldose reductase inhibitors on (A) sciatic endoneurial nutritive blood flow, (B) mean systemic blood pressure (BP) and (C) endoneurial vascular conductance (VC) in rats. NC, non-diabetic group, $n=10$; NSDI, non-diabetic group treated for 2 weeks with the sorbitol dehydrogenase inhibitor, WAY-135706 $\left(250 \mathrm{mg} \cdot \mathrm{kg}^{-1} \cdot \mathrm{day}^{-1}\right), \mathrm{n}=10$; DC, 8-week diabetic control group, $n=10$; DSDI, 8-week diabetic group treated for the final 2 weeks with WAY-135706 $\left(250 \mathrm{mg} \cdot \mathrm{kg}^{-1} \cdot \mathrm{day}^{-1}\right), \mathrm{n}=10$; DARI, 8-week diabetic group treated for the final 2 weeks with WAY-121509 $\left(10 \mathrm{mg} \cdot \mathrm{kg}^{-1} \cdot \mathrm{day}^{-1}\right), \mathrm{n}=10$. Data are mean + SEM. Statistics: flow, NC vs D, DSDI, $p<0.001$; NC vs NSDI, $p<0.01$; NC vs DARI, $p<0.05$; NSDI vs DC, DSDI, $p<0.001$; DARI vs DC, DSDI, $p<0.001$. Blood pressure, NC vs DC, DARI, $p<0.05$. Vascular conductance, NC vs D, DSDI, $p<0.001$; NSDI vs DC, DSDI, $p<0.001$; DARI vs DC, DSDI, $p<0.001$

endoneurial nutritive vascular conductance (Fig. 4C), the small deficits apparent from the blood flow data in ARI-treated diabetic and SDI-treated non-diabetic rats disappeared compared to the nondiabetic group. However, vascular conductance in the untreated diabetic group was $41.2 \pm 3.6 \%$ reduced $(p<0.001)$ and a $49.8 \pm 2.6 \%$ deficit $(p<0.001)$ persisted with SDI-treated diabetes; for both of these groups, vascular conductance was also significantly depressed $(p<0.001)$ compared to the ARI-treated diabetic group.

The hydrogen clearance technique also allows the measurement of total endoneurial perfusion, a composite of nutritive, large vessel and arteriovenous shunt flows [27]. Composite flow (Fig. 5 A) and conductance (Fig. 5B) were decreased by diabetes to the 

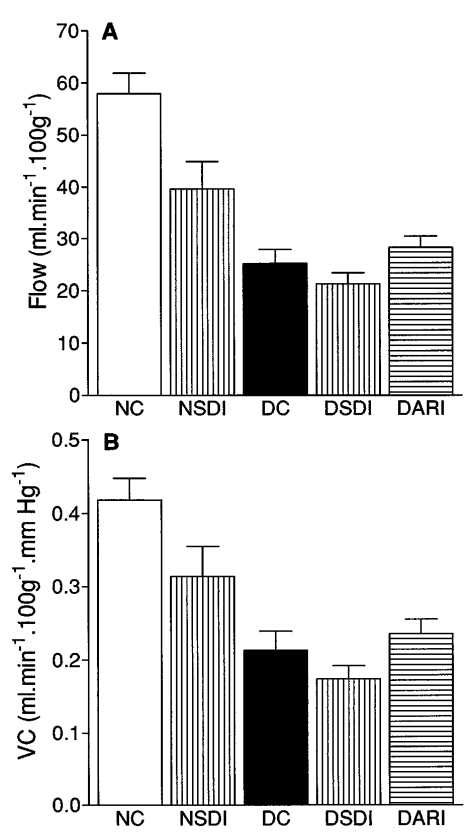

Fig. 5A , B. Effects of diabetes, sorbitol dehyrogenase and aldose reductase inhibitors on (A) sciatic composite endoneurial blood flow and (B) composite vascular conductance (V C) in rats. $\mathrm{NC}$, non-diabetic group, $\mathrm{n}=10$; NSDI, non-diabetic group treated for 2 weeks with the sorbitol dehydrogenase inhibitor, WAY-135706 $\left(250 \mathrm{mg} \cdot \mathrm{kg}^{-1} \cdot \mathrm{day}^{-1}\right), \mathrm{n}=10$; DC, 8-week diabetic control group, $\mathrm{n}=10$; DSDI, 8 -week diabetic group treated for the final 2 weeks with WAY-135706 (250 mg. $\mathrm{kg}^{-1} \cdot$ day $^{-1}$ ), $\mathrm{n}=10$; DARI, 8-week diabetic group treated for the final 2 weeks with WAY-121509 $\left(10 \mathrm{mg} \cdot \mathrm{kg}^{-1} \cdot \mathrm{day}^{-1}\right)$, $\mathrm{n}=10$. Data are mean + SEM. Statistics: flow, NC vs DC, DSDI, DARI, $p<0.001 ; \mathrm{NC}$ vs NSDI, $p<0.01 ;$ NSDI vs DSDI, $p<0.01$. Vascular conductance, NC vs DC, DSDI, DARI, $p<0.001 ; \mathrm{NC}$ vs NSDI, $p<0.05$; NSDI vs DSDI, $\mathrm{p}<0.01$

extent of $56.5 \pm 4.7 \%(p<0.001)$ and $49.0 \pm 6.2 \%$ $(p<0.001)$, respectively. This was not significantly altered by ARI or SDI treatment, values remaining reduced $(p<0.001)$ compared to the non-diabetic group. In addition, for the SDI-treated non-diabetic group, composite flow and conductance were diminished by $31.6 \pm 9.1 \% \quad(p<0.01)$ and $24.9 \pm 10.0 \%$ $(p<0.05)$, respectively compared to non-diabetic rats, although these measures remained significantly greater $(p<0.05)$ than for untreated diabetes.

\section{Discussion}

The data show that the SDI, WAY-135706, had a pronounced biochemical effect in several tissues. Sorbitol elevation was greater than noted in other SDI studies for nerve, lens and erythrocytes [33, 34]. An earlier study reported 8.7 and 1.4-fold increases in nerve and erythrocytes of non-diabetic rats treated with $100 \mathrm{mg} \cdot \mathrm{kg}^{-1}$ of SDI157 (the pro-drug for WAY-135706) and a 2.9-fold elevation in lens for $50 \mathrm{mg} \cdot \mathrm{kg}^{-1}$ [34]. This compares with 11.5, 6.4 and 17.4-fold changes, respectively, noted in our study. A second report [33] showed 2-4-fold sorbitol increases with S-0773 (equivalent to SDI157) in ocular tissues, sciatic nerve and blood of diabetic rats using doses of $50-150 \mathrm{mg} \cdot \mathrm{kg}^{-1}$. Fructose has been examined in less detail; $150 \mathrm{mg} \cdot \mathrm{kg}^{-1} \mathrm{~S}-0773$ reduced diabetic levels by 50,70 and $50 \%$ for retina, nerve and lens, respectively [33]. Inhibition in our study was higher, 90,95 and $93 \%$, respectively, and comparable to that for ARI treatment. This is important for potential effects on nerve function because a very high polyol pathway blockade is necessary to correct NCV deficits in diabetic rats $[6,11,18]$.

Elevated kidney fructose levels were barely altered by both the SDI and ARI, suggesting that much of the increase in diabetes comes from a source other than the polyol pathway. The ARI, ponalrestat, only partially decreased kidney fructose in diabetic rats [50], and in isolated glomeruli exposed to a high glucose concentration, tolrestat suppressed sorbitol production without affecting fructose levels [51]. Deleterious changes in renal structure and function have been attributed to increased AGE formation in diabetes [52]. If fructosylation is an important source of AGEs [30], then the data suggest that SDI treatment would be ineffective in protecting against these renal changes. For diaphragm, diabetes did not increase fructose, suggesting low sorbitol dehydrogenase activity or high fructose permeability. The fructose lowering in SDI-treated non-diabetic rats and a 6-fold sorbitol elevation for SDI-treated diabetes suggest a combination of these factors. Thus, SDI-induced fructose reductions are tissue dependent, probably reflecting a heterogeneity of fructose sources and differing activities of the two polyol pathway enzymes.

A partial reciprocity between sorbitol and myoinositol levels was noted for nerve and lens, in accordance with a role as a compensatory osmolyte [20, 53]. This may be reflected by changes in nerve water content. Thus, osmolyte levels (sorbitol, fructose and myo-inositol) were approximately $65 \mathrm{nmol} \cdot \mathrm{mg}$ protein $^{-1}$ in nerves from non-diabetic rats compared to 145 and $157 \mathrm{nmol} \cdot \mathrm{mg}$ protein $^{-1}$ in diabetic and SDItreated diabetic groups. For SDI-treated non-diabetic and ARI-treated diabetic rats, water content was unchanged and osmolyte levels were 72 and 37 nmo$1 \cdot \mathrm{mg}$ protein $^{-1}$, respectively. NCV was unaffected in SDI-treated non-diabetic rats although nerve sorbitol levels were similar to those found in untreated diabetes. In SDI-treated diabetic rats, nerve polyol accumulation approached that of galactosaemic rats which have marked NCV deficits [1, 54]. There was no worsening of NCV by these added potential osmotic insults, which provides further evidence against the involvement of osmotic disruption in the aetiology of NCV deficits $[1,19,55]$. This agrees with the conclusions from ARI dose-response studies, where 
NCV correlated poorly with polyol levels, but showed a strong relationship to changes in nerve blood flow $[6,11]$.

In renal medulla, sorbitol production has a role in cell-volume regulation [55]. However, medulla myoinositol was not affected by diabetes, SDI or ARI treatment, implying that it has no osmotic function. A $23 \%$ diabetic myo-inositol deficit in renal cortex was unaffected by ARI or SDI treatment, indicating dissociation from polyol pathway effects. While ARI and myo-inositol treatments partially protect against early increases in glomerular filtration and albumin excretion in diabetic rats [56, 57], myo-inositol does not prevent chronic renal changes [58]. Myo-inositol was unaltered by diabetes in retina and aorta, implying that it is not a major factor in the complications of these tissues. Diabetes increased diaphragm myoinositol levels, in agreement with other findings for striated muscle $[59,60]$. This was unaffected by ARI and SDI treatment, indicating a minimal role in polyol pathway-related myopathy [61].

SDI treatment had no effect on diabetic motor or sensory NCV deficits despite a very high suppression of sciatic nerve fructose production by the second half of the polyol pathway. In contrast, ARI treatment, which reduced flux through both halves of the polyol pathway, almost completely restored nerve function. Thus, the first polyol pathway reaction must make the major contribution to experimental diabetic neuropathy. In galactose-fed rats, galactose is converted to galactitol by aldose reductase, however, unlike sorbitol, galactitol is not further metabolised by sorbitol dehydrogenase [1]. In this model, stimulation of the aldose reductase step leads to ARI-preventable changes in nerve function and morphology resembling those of diabetes [54, 62-65]. The importance of aldose reductase is also emphasised by the exacerbated NCV deficits seen in diabetic and galactosaemic mice transgenic for human aldose reductase [66].

Time-course considerations influenced the experimental design; NCV in our model was corrected in 7-11 days by the ARIs, ZD5522 [6] and WAY121509 (Dines, Cameron and Cotter, unpublished observations). Biochemical changes in rat nerves in vivo occur within a few hours of treatment with pyrimidine-based SDIs and ARIs [1, 34]. Thus, an agent that does not correct NCV deficits over the same period as ARIs cannot be acting via mechanisms dependent on the immediate consequences of polyol pathway flux (sorbitol and fructose accumulation and changes in NADPH/NADP ${ }^{+}$and $\mathrm{NADH} / \mathrm{NAD}^{+}$ratios). The putative redox change in pseudohypoxia [31], an increased NADH/NAD ${ }^{+}$ratio, falls into this category, therefore, the NCV data for SDI treatment suggest that this hypothesis does not apply to nerve.

A long-term study on caudal NCV showed no effect of SDI157 (100 mg $\left.\mathrm{kg}^{-1}\right)$ over 43-221 days, although a small improvement was alleged at 15 days [34]. Another caudal nerve investigation claimed a modest effect of S-0773 (100-150 mg $\cdot \mathrm{kg}^{-}$ $\left.{ }^{1}\right)$ over 4 weeks [33]; however, neither analysis took account of multiple comparisons to protect against type 1 errors; statistical significance disappears when Bonferroni or Student-Newman-Keuls corrections are applied. Caudal nerve studies also make conflicting and statistically dubious claims of increased [34] or decreased [33] NCV in SDI-treated non-diabetic rats. The average trend is in accord with this study which found no NCV effects of the SDI in non-diabetic rats.

A recent brief report claimed that 14 weeks of SDI treatment $\left(200 \mathrm{mg} \cdot \mathrm{kg}^{-1} \mathrm{CP} 166572\right.$, equivalent to WAY-135706), caused an $82 \%$ reduction of nerve fructose and prevented tibial-interosseous motor NCV deficits in diabetic rats [67]. This is at variance with the caudal nerve results [33], and contrasts with the sciatic and saphenous nerve data despite $95 \%$ inhibition of fructose accumulation; the reason for the discrepancy is unclear. It is unlikely to depend on the use of a reversal rather than a prevention paradigm in this study; NCV is rapidly corrected by a variety of interventions in the nerve branches examined [28]. An alternative explanation is that while shortterm NCV effects depend on the first half of the polyol pathway, long-term effects might depend on prevention of fructosylation and AGE accumulation [30] in nerve and vasa nervorum. In this respect, while SDIs could reduce AGE formation, reversal treatment would be less effective as the AGEs initially formed during the untreated diabetic period would continue their deleterious free-radical producing reactions. However, in contrast to this explanation, aminoguanidine, which prevents AGE formation, rapidly corrects established NCV deficits within 10 days of treatment [68]. Thus, a long-term SDI action in the absence of short-term effects suggests drug-specific actions unrelated to the polyol pathway. Further NCV studies using structurally dissimilar SDIs are needed to clarify this point. It could also be argued that myo-inositol changes, uncorrected by SDI treatment of diabetic rats [33, 67], are critical for NCV. However, vasodilators, essential fatty acids and antioxidants correct NCV despite reduced myoinositol levels, and myo-inositol treatment does not alter NCV in our model [6, 10, 28, 43].

While the ARI corrected impaired sciatic endoneurial nutritive blood flow in diabetic rats, the SDI was without effect. The diabetic deficit and the effect of ARI treatment are consistent with a large number of reports [6, 8-11, 27, 28, 42, 45-48]. ARIs normalise nutritive perfusion primarily by diverting arteriovenous shunt flow to the capillary bed $[6,10,11]$. This probably results from improved protection against oxidative stress by the glutathione redox cycle, which like the first but not the second reaction of the polyol 
pathway, is NADPH-dependent $[6,10,11,28]$. Similar blood flow and NCV changes were found for treatment with the antioxidant and glutathione substrate, $\mathrm{N}$-acetyl-L-cysteine [69]. Thus, ARI treatment has little effect on total endoneurial flow. There is a good correlation between NCV and nutritive flow (but not total endoneurial flow) in diabetic rats when data from several therapeutic intervention studies are pooled [70]; therefore, a lack of action on nutritive perfusion probably underlies the poor SDI effect on NCV. An earlier study attempted to estimate nerve perfusion using microsphere entrapment, the results being interpreted as an increase in flow with diabetes which was partially prevented by SDI treatment [33]. Data obtained by the microsphere method, however, do not agree with other invasive and non-invasive techniques for flow assessment in nerve, therefore it is of questionable validity $[27,28,41]$. Nonetheless, reduced microsphere entrapment by SDI treatment in diabetic rats indicates a vascular effect, albeit not directly related to nutritive blood flow. Platelet aggregation, thrombus formation and leucocyte-endothelium interactions are increased in diabetes [71,72]. It is possible that SDI treatment might decrease one or more of these factors, which could explain reduced microsphere trapping and suggests a direction for future research. SDI treatment of non-diabetic rats reduced total endoneurial perfusion, although this did not impinge on nutritive flow or NCV [10]. The mechanism is unclear; SDIs accelerate cataract formation and depress lens glutathione levels while ARIs have the opposite effect [34]. If SDIs also reduce vasa nervorum glutathione, impaired antioxidant activity would alter blood flow, as noted in pro-oxidant-treated non-diabetic rats [23].

In conclusion, ARIs have beneficial actions on nerve perfusion and conduction in experimental diabetes, whereas SDIs lack these effects. Thus, the conversion of glucose to sorbitol via aldose reductase is the crucial polyol pathway step in rats, contributing to diabetic neuropathy by reducing endoneurial capillary perfusion. SDI-induced sorbitol accumulation may exacerbate the pathogenesis of some diabetic complications such as cataracts, and a tendency towards impaired total nerve perfusion suggests that while SDIs are a valuable research tool they would be unsuitable for therapeutic intervention.

A cknowledgement. N.E. C. was supported by a Wellcome Trust Research Leave Fellowship.

\section{References}

1. Dvornik D (1987) Hyperglycemia in the pathogenesis of diabetic complications. In: Porte D (ed) Aldose reductase inhibition. An approach to the prevention of diabetic complications. Biomedical information corporation, New York, pp 69-151
2. Tomlinson DR, Holmes PR, Mayer JH (1982) Reversal, by treatment with an aldose reductase inhibitor, of impaired axonal transport and motor nerve conduction velocity in experimental diabetes mellitus. Neurosci Lett 21: 189-193

3. Hotta N, Kakuta H, Fukasawa H et al. (1985) Effects of a fructose-rich diet and the aldose reductase inhibitor, ONO-2235, on the development of diabetic neuropathy in streptozotocin-treated rats. Diabetologia 28: 176-180

4. Cameron NE, Leonard MB, Ross IS, Whiting PH (1986) The effects of sorbinil on peripheral nerve conduction velocity, polyol concentrations and morphology in the streptozotocin-diabetic rat. Diabetologia 29: 168-174

5. Yagihashi S, Kamijo M, Ido Y, Mirrlees DJ (1990) Effects of long-term aldose reductase inhibition on development of experimental diabetic neuropathy, ultrastructural and morphometric studies of sural nerve in streptozotocin-induced diabetic rats. Diabetes 39: 690-696

6. Cameron NE, Cotter MA, Dines KC, Maxfield EK, Carey F, Mirrlees DJ (1994) Aldose reductase inhibition, nerve perfusion, oxygenation and function in streptozotocin-diabetic rats: dose-response considerations and independence from a myo-inositol mechanism. Diabetologia 37: 651-663

7. Stevens MJ, Dananberg J, Feldman EL et al. (1994) The linked roles of nitric oxide, aldose reductase and $\left(\mathrm{Na}^{+}\right.$, $\mathrm{K}^{+}$)-ATPase in the slowing of nerve conduction in the streptozotocin diabetic rat. J Clin Invest 94: 853-859

8. Calcutt NA, Mizisin AP, Kalichman MW (1994) Aldose reductase inhibiton, Doppler flux and conduction in diabetic rat nerve. Eur J Pharmacol 251: 27-33

9. Hotta N, Kaskuta H, Fukasawa H et al. (1995) Effect of a potent new aldose reductase inhibitor (5-(3-thienyl)tetrazol-1-yl)acetic acid (TAT), on diabetic neuropathy in rats. Diabetes Res Clin Pract 27: 107-117

10. Cameron NE, Cotter MA, Hohman TC (1996) Interactions between essential fatty acid, prostanoid, polyol pathway and nitric oxide mechanisms in the neurovascular deficit of diabetic rats. Diabetologia 39: 172-182

11. Cameron NE, Cotter MA, Dines KC, Hohman TC (1996) Reversal of defective peripheral nerve conduction velocity, nutritive endoneurial blood flow and oxygenation by a novel aldose reductase inhibitor, WAY-121509, in streptozotocin-diabetic rats. J Diabet Complications 10: 43-53

12. Love A, Cotter MA, Cameron NE (1995) Impaired myelinated fibre regeneration following freeze-injury in rats with streptozotocin-induced diabetes: involvement of the polyol pathway. Brain Res 703: 105-110

13. Engerman RL, Kern TS, Larson ME (1994) Nerve conduction and aldose reductase inhibition during 5 years of diabetes or galactosaemia in dogs. Diabetologia 37: 141144

14. Sima AAF, Bril V, Nathaniel V et al. (1988) Regeneration and repair of myelinated fibers in sural-nerve biopsy specimens from patients with diabetic neuropathy treated with sorbinil. New Eng J Med 319: 548-555

15. Boulton AJM, Levin S, Comstock J (1990) A multicentre trial of the aldose-reductase inhibitor, tolrestat, in patients with symptomatic diabetic neuropathy. Diabetologia 33: 431-437

16. Santiago JV, Sönksen PH, Boulton AJM et al. (1993) Withdrawal of the aldose reductase inhibitor tolrestat in patients with diabetic neuropathy: effects on nerve function. J Diabet Complications 7: 170-178

17. Sima AAF, Greene DA, Brown MB et al. (1993) Effect of hyperglycemia and the aldose reductase inhibitor tolrestat on sural nerve biochemistry and morphometry in advanced diabetic peripheral polyneuropathy. J Diabet Complications 7: 157-169 
18. Cameron NE, Cotter MA (1992) Dissociation between biochemical and functional effects of the aldose reductase inhibitor ponalrestat on peripheral nerve in diabetic rats. $\mathrm{Br}$ J Pharmacol 107: 939-944

19. Gabbay KH (1973) The sorbitol pathway and the complications of diabetes. N Engl J Med 288: 831-836

20. Stevens MJ, Lattimer SA, Kamijo M, Van Huysen C, Sima AAF, Greene DA (1993) Osmotically induced nerve taurine depletion and the compatible osmolyte hypothesis in experimental diabetic neuropathy. Diabetologia 36: 608614

21. Greene DA, Lattimer SA (1984) Relationship of polyol (sorbitol) pathway inhibition to a myoinositol-mediated defect in sodium-potassium ATPase activity. Diabetes 33: $712-716$

22. Kashiwagi A, Asahina T, Ikebuchi M et al. (1994) Abnormal glutathione metabolism and increased cytotoxicity caused by $\mathrm{H}_{2} \mathrm{O}_{2}$ in human umbilical vein endothelial cells cultured in high glucose medium. Diabetologia 37: 264-269

23. Cameron NE, Cotter MA, Archibald V, Dines KC, Maxfield EK (1994) Anti-oxidant and pro-oxidant effects on nerve conduction velocity, endoneurial blood flow and oxygen tension in non-diabetic and streptozotocin-diabetic rats. Diabetologia 37: 449-459

24. Cotter MA, Love A, Watt MJ, Cameron NE, Dines KC (1995) Effects of natural free radical scavengers on peripheral nerve and neurovascular function in diabetic rats. Diabetologia 38: 1285-1294

25. Cameron NE, Cotter MA (1992) Impaired contraction and relaxation in aorta from streptozotocin-diabetic rats: role of polyol pathway activity. Diabetologia 35: 1011-1019

26. Cameron NE, Cotter MA, Dines KC, Maxfield EK (1993) Pharmacological manipulation of vascular endothelium in non-diabetic and streptozotocin-diabetic rats: effects on nerve conduction, hypoxic resistance and endoneurial capillarization. Diabetologia 36: 516-522

27. Low PA, Lagerlund TD, McManis PG (1989) Nerve blood flow and oxygen delivery in normal, diabetic and ischemic neuropathy. Int Rev Neurobiol 31: 355-438

28. Cameron NE, Cotter MA (1994) The relationship of vascular changes to metabolic factors in diabetes mellitus and their role in the development of peripheral nerve complications. Diabetes Metab Rev 10: 189-224

29. Tesfaye S, Malik R, Ward JD (1994) Vascular factors in diabetic neuropathy. Diabetologia 37: 847-854

30. Brownlee M (1992) Glycation products and the pathogenesis of diabetic complications. Diabetes Care 15: 1835-1843

31. Williamson JR, Chang K, Frangos M, et al. (1993) Hyperglycemic pseudohypoxia and diabetic complications. Diabetes 42: 801-813

32. Ido Y, McHowat J, Chang KC, et al. (1994) Neural dysfunction and metabolic imbalances in diabetic rats: prevention by acetyl-L-carnitine. Diabetes 43: 1469-1477

33. Tilton RG, Chang K, Nyengaard JR, Van Den Enden M, Ido Y, Williamson JR (1995) Inhibition of sorbitol dehydrogenase: effects on vascular and neural dysfunction in streptozotocin-induced diabetic rats. Diabetes 44: 234-242

34. Geisen K, Utz R, Grötsch H, Lang HJ, Nimmesgern H (1994) Sorbitol-accumulating pyrimidine derivatives. Arzneim-Forsch/Drug Res 44: 1032-1043

35. Malmas MS, Hohman TC, Millen J (1994) Novel spirosuccinimide aldose reductase inhibitors derived from isoquinoline-1,3-diones: 2-[(4-bromo-2-flourophenyl)-methyl]-6-fluorospiro-[isoquinoline-4(1H), 3' pyrrolidine]$1,2^{\prime} 3,5^{\prime}(2 \mathrm{H})$-tetrone and congeners. J Med Chem 37: 2043-2058
36. Guerrant GO, Moss CW (1984) Determination of monosaccharides as aldonitrile O-methyloxamine, alditol and cyclitol acetate derivatives by gas chromatography. Anal Chem 56: 633-638

37. Peterson GL (1977) A simplification of the protein assay method of Lowry et al., which is more generally applicable. Anal Biochem 83: 346-356

38. Cameron NE, Cotter MA, Low PA (1991) Nerve blood flow in early experimental diabetes in rats: relation to conduction deficits. Am J Physiol 261: E1-E8

39. Cameron NE, Dines KC, Cotter MA (1994) The potential contribution of endothelin-1 to neurovascular abnormalities in streptozotocin-diabetic rats. Diabetologia 37: 12091215

40. Chang K, Ido Y, Lejeune W, Monafo W, Williamson J (1995) Invasive methodology is unsuitable for assessing nerve blood flow in diabetes. Diabetes 44 [Suppl 1]: $68 \mathrm{~A}$ (Abstract)

41. Heyman MA, Payne BD, Hoffman JIE, Rudolf AM (1977) Blood flow measurements with radionuclide-labelled particles. Prog Cardiovasc Dis 20: 55-79

42. Monafo WW, Eliasson SG, Shimazaki S, Sugimoto H (1987) Regional blood flow in resting and stimulated sciatic nerve of diabetic rats. Exp Neurol 99: 607-614

43. Maxfield EK, Cameron NE, Cotter MA, Dines KC (1993) Angiotensin II receptor blockade improves nerve function, modulates nerve blood flow and stimulates endoneurial angiogenesis in streptozotocin-diabetic rats. Diabetologia 36: 1230-1237

44. Kalichman MW, Lalonde AW (1991) Experimental nerve ischemia and injury produced by cocaine and procaine. Brain Res 565: 34-41

45. Kapelle AC, Biessels GJ, Van Buren T, Erkelens DW, De Wildt DJ, Gispen WH (1993) Effects of nimodipine on sciatic nerve blood flow and vasa nervorum responsiveness in the diabetic rat. Eur J Pharmacol 250: 43-49

46. Wright RA, Nukuda H (1994) Vascular and metabolic factors in the pathogenesis of experimental diabetic neuropathy in mature rats. Brain 117: 1395-1407

47. Yasuda H, Sonobe M, Yamashita M et al. (1989) Effect of prostaglandin $\mathrm{E}_{1}$ analogue TFC 612 on diabetic neuropathy in streptozocin-induced diabetic rats comparison with aldose reductase inhibitor ONO 2235. Diabetes 38: 832-838

48. Stevens EJ, Carrington AL, Tomlinson DR (1994) Nerve ischaemia in diabetic rats: time-course of development, effects of insulin treatment plus comparison of streptozotocin and BB models. Diabetologia 37: 43-48

49. Williamson J, Chang K, Lejeune W, Ido Y (1995) Sciatic endoneurial vascular resistance is decreased in nonketotic but not in ketotic diabetic rats. Diabetes 44 [Suppl 1]: $224 \mathrm{~A}$ (Abstract)

50. Sochor M, Hunjara S, McLean P (1988) The effect of aldose reductase inhibitor Statil (ICI 128436) on glucose over-utilization in kidney of diabetic rats. Biochem Pharmacol 37: 3349-3356

51. Tilton RG, Baier LD, Harlow JE, Smith SR, Ostrow E, Williamson JR (1992) Diabetes-induced glomerular dysfunction: links to a more reduced cytosolic ratio of $\mathrm{NADH} /$ $\mathrm{NAD}^{+}$. Kidney Int 41: 778-788

52. Soulis-Liparota T, Cooper M, Papazoglou D, Clarke B, Jerums G (1991) Retardation by aminoguanidine of development of albuminuria, mesangial expansion, and tissue fluorescence in streptozocin-induced diabetic rat. Diabetes 40: 1328-1334

53. Hohman TC, Carper D (1990) Hypertonic stress induces aldose reductase and myo-inositol accumulation in lens epithelial, kidney endothelial and Chinese hamster ovary 
cells. In: Sakimoto N, Kinoshita JH, Kador PF, Hotta N (eds) Current concepts of aldose reductase and its inhibitions. Elsevier, Amsterdam, pp 31-41

54. Dines KC, Cotter MA, Cameron NE (1995) Nerve function in galactosaemic rats: effects of evening primrose oil and doxazosin. Eur J Pharmacol 281: 303-309

55. Burg MB, Kador PF (1988) Sorbitol, osmoregulation and the complications of diabetes. J Clin Invest 81: 635-640

56. Chang WP, Dimitriadis E, Allen T, Dunlap ME, Cooper M, Larkins RG (1991) The effect of aldose reductase inhibitors on glomerular prostaglandin production and urinary albumin excretion in experimental diabetes mellitus. Diabetologia 34: 225-231

57. Goldfarb S, Ziyadeh FN, Kern EFO, Simmons DA (1991) Effects of polyol pathway inhibition and dietary myo-inositol on glomerular hemodynamic function in experimental diabetes mellitus in rats. Diabetes 40: 465-471

58. Tilton RG, Faller AM, LaRose LS, Burgan J, Williamson JR (1993) Dietary myo-inositol supplementation does not prevent retinal and glomerular vascular structural changes in chronically diabetic rats. J Diabet Complications 7: 188198

59. Cotter MA, Cameron NE, Robertson S, Ewing I (1993) Polyol pathway-related skeletal muscle contractile and morphological abnormalities in diabetic rats. Exp Physiol 78: $139-155$

60. Cameron NE, Cotter MA, Robertson S (1989) Contractile properties of cardiac papillary muscle in streptozotocin-diabetic rats and the effects of aldose reductase inhibition. Diabetologia 32: 365-370

61. Cameron NE, Cotter MA, Robertson S (1990) Changes in skeletal muscle contractile properties in streptozotocin-diabetic rats and the role of the polyol pathway and hypoinsulinemia. Diabetes 39: 460-465

62. Low PA, Schmelzer JD (1983) Peripheral nerve conduction studies in galactose-poisoned rats. J Neurol Sci 59: 415-421
63. Cameron NE, Cotter MA, Robertson S, Cox D (1992) Muscle and nerve dysfunction in rats with experimental galactosaemia. Exp Physiol 77: 89-108

64. Mizisin AP, Powell HC (1993) Schwann cell injury is attenuated by aldose reductase inhibition in galactose intoxication. J Neuropathol Exp Neurol 52: 78-86

65. Kamijo M, Basso M, Cherian PV, Hohman TC, Sima AAF (1994) Galactosemia produces ARI-preventable nodal changes similar to those of diabetic neuropathy. Diabetes Res Clin Pract 25: 117-129

66. Yagihashi S (1995) Pathology and pathogenetic mechanisms of diabetic neuropathy. Diabetes Metab Rev 11: $193-225$

67. Oates PJ, Ido Y, Mylari BL, Williamson JR (1995) Peripheral neuropathy in diabetic rats is prevented by inhibition of sorbitol dehydrogenase or aldose reductase. Diabetologia 38 [Suppl 1]: A232 (Abstract)

68. Cameron NE, Cotter MA (1996) Rapid reversal by aminoguanidine of the neurovascular effects of diabetes in rats: modulation by nitric oxide synthase inhibition. Metabolism 45: $1147-1152$

69. Love A, Cotter MA, Cameron NE (1996) Effects of the sulphydryl donor $\mathrm{N}$-acetyl-L-cysteine on nerve conduction, perfusion, maturation and regeneration following freeze damage in diabetic rats. Eur J Clin Invest 26: 698-706

70. Cameron NE, Cotter MA (1995) Mechanisms underlying impaired peripheral nerve perfusion and endoneurial oxygenation in experimental diabetes: potential treatment strategies. In: Hotta N, Greene DA, Ward JD, Sima AAF, Boulton AJM (eds) Diabetic neuropathy: new concepts and insights. Elsevier, Amsterdam, pp 3-15

71. Ceriello A (1993) Coagulation activation in diabetes mellitus: the role of hyperglycaemia and therapeutic prospects. Diabetologia 36: 1119-1125

72. Moore SA, Bohlen HG, Miller BG, Evan AP (1985) Cellular and vessel wall morphology of cerebral cortical arterioles after short-term diabetes in adult rats. Blood Vessels 22: $265-277$ 